\title{
A cross-impact analysis of eight economic parameters in Iceland in the context of Arctic climate change
}

\author{
Pórður Víkingur Friðgeirsson and Freydís Dögg Steindórsdóttir ${ }^{1}$
}

\begin{abstract}
Previous studies have identified eight parameters as being the most influential on the Icelandic economy in the light of prevailing climate change. This study aims to investigate these economic parameters in relation to the Arctic Region and the Icelandic economy. The study is rooted in the theoretical framework of decision analysis and is intended to contribute to strategic and tactical decision making in the context of Iceland and developments resulting from climate changes in the Arctic Region. The study results could eventually lead do a "What if" decision model, where multiple scenarios can be analyzed by inserting/entering different probabilities of a particular outcome. The parameters under screening/review are interdependent, and to construct a decision model these interdependencies must be assessed. The Delphi method was employed, along with the cross-impact analysis, to shed light on the interconnections between eight of these parameters. Diverse views are revealed concerning the impacts between parameters, although a consensus was reached in the second round of the survey. In some instances, the level of agreement was high, while other estimates showed a wide range of responses. The diversity in answers suggests a higher level of uncertainty regarding some parameters and events compared to others. The survey also indicates how challenging the Delphi and cross-impact methods are in terms of the involvement of experts. However, when data is scarce, these methods provide significant insight.
\end{abstract}

JEL flokkun: E17, E66, F47, F62, L78, M21, M38, O11, O22, O33, P21, R10, Z30

Keywords: Arctic region; economic parameters; decision analysis; delphi method; cross-impact analysis.

1 Pórður Víkingur Friðgeirsson, Assistant Professor, School of Science and Engineering, Reykjavík University. E-mail: thordurv@ru.is. Freydís Dögg Steindórsdóttir, MSc in engineering management. E-mail: freydiss12@ru.is.

This work is licensed under a Creative Commons Attribution 4.0 License.

DOI: https://doi.org/10.24122/tve.a.2018.15.1.3

(C) Tímarit um viðskipti og efnahagsmál

www.efnahagsmal.is 


\section{Introduction}

\subsection{Background}

Interest in the Arctic Region has increased immensely over recent years (Ding et al, 2017). This is due to a substantial decrease in the multiyear ice area in the Arctic, with a record decline in 2008 and again in 2012 (Comiso, 2012). Although the ice area has recovered to some extent in individual years, there is still a trend of rapid decline per decade (NSIDC, 2016). As a result, the Arctic coasts will likely be free of ice all summer by the middle of this century (Laulajainen, 2009). This has opened the doors to industrial opportunities, as well as to commercial sailing through the Arctic Sea Route. There is also, however, great uncertainty regarding the consequences of increasing activity in the Arctic, and how this will affect the environment, society and economy in the regions surrounding the Arctic (Lloyd's, 2011; Jóhannesdóttir \& Cook, 2015).

With increased shipping activity comes a higher risk of accidental or illegal oil spills and currently there is a lack of marine infrastructure to respond to such incidents and other emergency safety issues (Ellis \& Brigham, 2009). Furthermore, Arctic residents are apprehensive about the impact on their culture and society, as well as the disruption of marine species, upon which they heavily rely.

To make matters more complicated, all these factors are interrelated, and treating each of them in isolation will not result in a comprehensive view of the developments north of the Arctic Circle. Taking everything above in to account, the countries surrounding the Arctic and their representatives now face the difficult task of economic decision making regarding their Arctic activities. Given the many uncertainties and possible scenarios, and the interdependency between parameters, a coherent overview of the problem would greatly benefit stakeholders and decision makers. This study aims to investigate some of the economic parameters, and their interrelations, pertaining to a decision model representing developments in the Arctic over the next 20 years, based on previous studies by Grímsdóttir (2014) and Guðmundsson (2015). In the previous studies, some 28 economic parameters were identified by stakeholder analysis. The most significant and dominant eight parameters were selected on the basis of weighted analysis by the stakeholders. A stochastic decision model with connected economic parameters could enhance our understanding of the positive and negative impact of different possible scenarios in Iceland. Arguably, the decision model could also be applied to other developed economies affected by the climate changes in the Arctic.

The Arctic Circle is specified as an approximation for the southern boundary of the midnight sun at an imaginary line situated at $66^{\circ} 32^{\prime} \mathrm{N}(\mathrm{AMAP}, 1998)$. The eight countries comprising the Arctic Region are: Canada, Denmark, Finland, Iceland, Norway, Russia, Sweden and the United States of America. These countries form the Arctic Council, which was established in 1996 with the signing of the Ottawa declaration, which gives the Arctic Council a broad approval to address issues relevant to the Arctic Region and its peoples (Arctic Council, 2016). In the last 20 years, the Arctic Council has focused mainly on environmental protection and sustainable development. Six working groups operate within the Arctic Council, each focusing on different aspects of issues regarding the Arctic. However, none of these working groups focus on the economic impact of increased activity in the Arctic Region. As mentioned above, there are many opportunities, challenges and uncertainties that arise as a result of the ongoing climate changes and melting of the Arctic ice cap.

The opportunities revolve around the natural gas the Arctic holds, and the rise of tourism and fisheries in the Arctic, which, amongst other things, can be attributed to easier access to the region. The Northeast Passage and the Northwest Passage, jointly referred to as the Arctic Sea Route, which can be seen in Figure 1, are expected to open up for yearround commercial shipping by the end of this century (Laulajainen, 2009). This will lead 
to more accessible discovery and exploitation of mineral resources, for example hydrocarbons, and possibly form a new pattern of raw material flows (ACIA, 2004). Substantial areas reaching beyond territorial waters are likely to gain economic value, and furthermore there will be an expansion northward in areas suitable for forestry and some types of agriculture. In addition to this, Icelandic ports could serve as hubs in the transshipment industry relating to the Arctic Region.

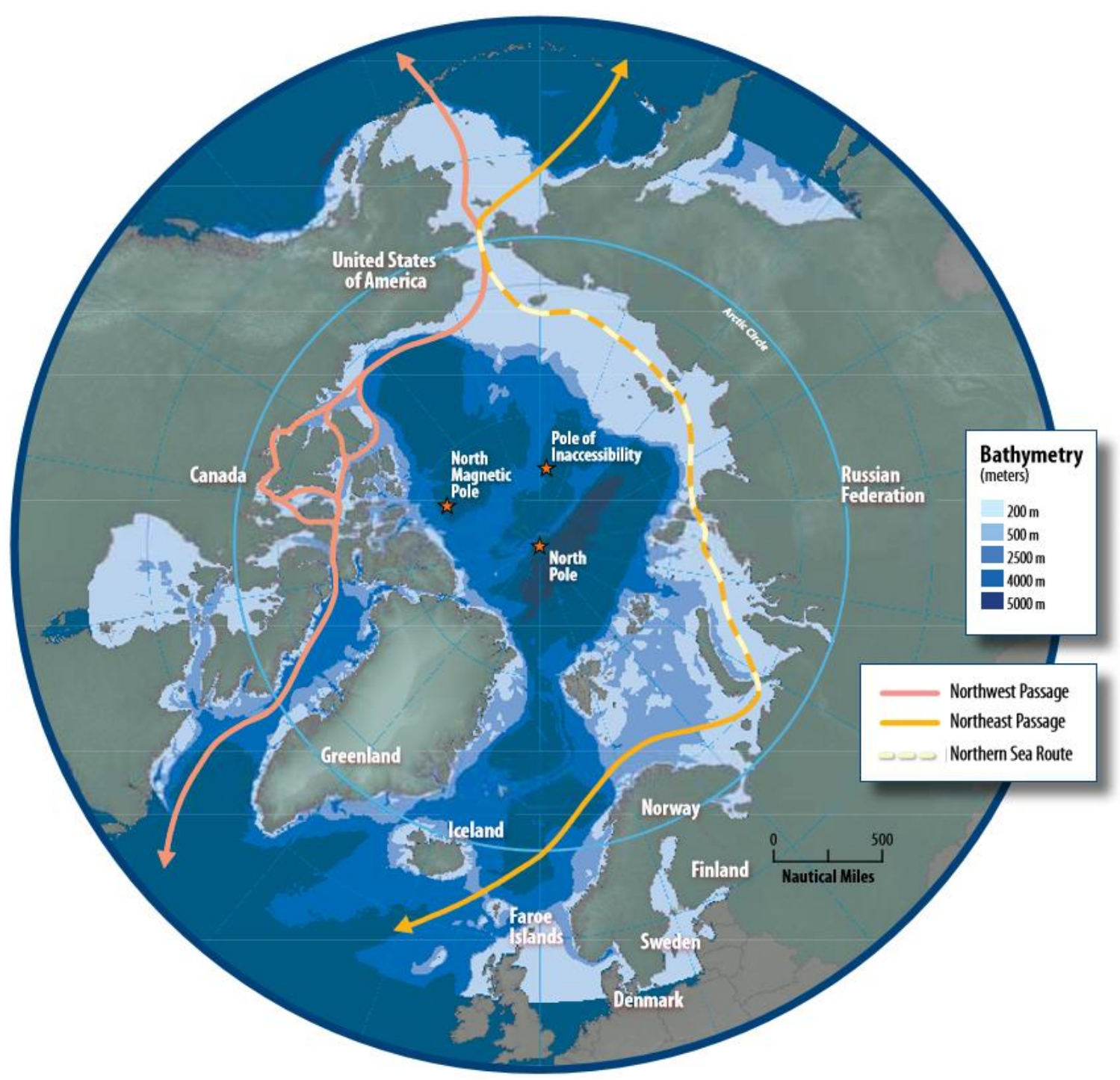

Figure 1. The Arctic sea route (Ellis \& Brigham, 2009, p. 17)

\subsection{Statement of problem}

Extreme weather conditions and a harsh natural environment have characterized the area north of the Arctic Circle for centuries, and so the area is relatively uncharted territory. This presents several difficulties for stakeholders interested in investing in the Arctic. The level of uncertainty is high, and the supply of accurate predictions is scarce, as precedents are non-existent. However, it is expected that business-related activities will escalate dramatically in the next ten to twenty years (Holthus, Clarkin \& Lorentzen, 2013; Lajeunesse, 2012). There are many variables to consider pertaining to environment, society, security and wildlife before embarking on economic ventures with undetermined outcomes. 


\subsection{Research questions}

The research questions are as follows:

- Can the interrelations between the 8 chosen parameters be determined?

- Which of the cross-impacts between chosen economic parameters convey the most uncertainty and risk?

- Which of the 8 economic parameters, if any, have no interrelation between them.

An economic parameter in this research is defined as: a variable that can influence cost and/or income directly or indirectly, for business life and government in the coming decades.

The paper is structured as follows: the theoretical framework is described, then the methodology, followed by the research process. The results are then presented, followed by discussion and final conclusion.

\subsection{Limitations}

The parameters that will ultimately influence decision making in the Arctic originate from different areas of expertise and form a much larger set than will be explored here. The focus in this research is on the economic parameters, already defined by Grímsdóttir (2014), and their impact factor on the Icelandic economy over the next 20 years. Furthermore, the interconnection between eight of the parameters is the main subject of this paper. There are legal and political issues, as well as environmental ones that will not be resolved in this research. Finding a balance between environmental and economic objectives is often complicated, quite apart from the political and ethical issues that come into play, but these matters will not be addressed here. The effect on the delicate ecosystem of the Arctic, although important, is not addressed in this study.

\section{Theoretical framework}

The study is grounded in decision theory and analysis which deals with decision making under uncertainty. The research is approached from the perspective of systems engineering, where models of various types are prevalent. First, there will be a discussion on decision theory and analysis. Next, the Delphi method will be described and finally, the theory of cross-impact analysis will be covered.

\subsection{Normative and descriptive theory}

When modern decision theory began developing in the mid-20th century, a distinction started to form/emerge, the distinction between two main approaches to decision theory on the one hand, normative decision theory, and on the other, descriptive decision theory.

Normative theory deals with how people should behave and make decisions in a rational way, while descriptive theory is about how people actually behave and make decisions in real life situations (Hansson, 1994). Likewise, normative models state what should happen if everything behaved according to certain theories, whereas descriptive models try to describe how things actually take place, without making any judgement as to how they should happen (Howard, 1988).

Although the line between descriptive and normative theory seems clear, many problems and their analysis involve aspects of both (French, 1995). Decision analysts use normative decision theories to help decision makers choose strategies for comparing consequences described by descriptive models of these strategies. This is commonly referred to as prescriptive analysis (French, 1995).

Behavioral decision theory was introduced in 1954 by the American psychologist Ward Edwards (Edwards, 1954). It was one of the first models to highlight the importance of 
subjective values and belief in judgment and decision making as the basis for predicting decision behavior.

\subsection{Decision analysis}

Confirming the distinction between normative and descriptive decision theory was an important step in the advancement of decision analysis and the development of methods to deal with complex decisions under multiple objectives or uncertainty. The role of decision analysis has changed significantly since earlier years, when the focus was often on finding an optimal solution. However, today in decision analysis discipline, the emphasis is on analysis of the complexity that decision makers face, or, as described by Keeney (1982, p. 821): “Decision analysis will not solve a decision problem, nor is it intended to. Its purpose is to produce insight and promote creativity to help decision makers make better decisions".

Modern decision analysis bases its foundation on a set of principles for analyzing decision problems (Keeney, 1982). The principles provide a sound basis for a systematic analysis, including judgement and values, to be applied to a range of decision problems. The focus of decision analysis is on the five elements common to all decision problems. These are: (1) A perceived need to accomplish some objectives, (2) several alternatives, one of which must be selected, (3) the consequences associated with alternatives are different, (4) uncertainty, usually about the consequences of each alternative and (5) the possible consequences are not all equally valued (Keeney, 1982).

The process of analyzing decision problems is based on the aforementioned axioms. As with the axioms, various scholars have outlined the process in a range of publications. Although the number of steps or phases and the emphasis on terminology are different, the processes described are much the same. Ronald A. Howard identifies three phases in the decision analysis procedure (Howard, 1966). First, there is the deterministic phase, second, the probabilistic phase, and finally, the post mortem phase. The first phase entails defining the decision, identifying alternatives, assigning value to outcomes, along with selecting variables and establishing their relationship. The second, probabilistic phase is where uncertainty and risk preference are considered and the best alternative selected. The post mortem phase is dedicated to analysis of the impact of uncertainties on the outcome and then the gathering of more information before finally, as the result of the analysis, a decision is taken on how to move forward.

\subsection{Delphi method}

This method is/comes in the form of a group communication process and is, in a sense, a controlled debate (Gordon, 1994; Hsu \& Sandford, 2007). It aims to achieve a convergence of opinion on the real-world issue at hand, and has been applied with success in many instances (Shortall, Davidsdottir \& Axelsson, 2015). However, sometimes consensus is not reached, and when that happens the reasons for contrasting positions become clear through the process (Gordon, 2009). Delphi should inspire genuine discussion, independent of personalities. Anonymity is essential to eliminate the influence of indoctrination by skillful speakers.The technique consists of a survey carried out in two or more rounds, where the outcome of the first round is provided to the participants in the second round (Cuhls, 2005). The Delphi method generates both qualitative and quantitative results and is based on explorative, predictive and normative elements (Cuhls, 2005). To sum up, the Delphi method can be defined as a technique for gathering judgements on complex subjects where other information is scarce (Yousuf, 2007).

\subsection{Cross-impact analysis}

The first step in the initial form of the cross-impact method was to select the events to be 
included in the analysis. The value of results obtained from the method rely heavily on the selection of events, because impacts excluded from the collection/selection are thereby excluded from the study. On the other hand, it is ill-advised to include impacts not significant to the study, since the number of interactions to be valued increases appreciably with each event added (Gordon, 1994). This is apparent when considering that the number of event pairs to be evaluated is equal to $n^{2}-n$ ( $n$ being the number of events).

When the set has been determined, the initial probability of each event must be estimated. This is the likelihood of the event taking place within a previously decided timeframe. The next step is to evaluate the conditional probabilities by asking what the posterior likelihood of event $\mathrm{m}$ would be if $\mathrm{n}$ occurred. The entire set of evaluations is completed for each event occurring and impacting all other events. Because of laws of probability, some inconsistencies in the estimations may arise, which require them to be reviewed before going further (Gordon, 1994). The final steps of the original cross-impact method then include calibrating the cross-impact matrix and, after that, analyzing how sensitive the system is to fluctuations in probabilities, both initial and conditional, of different events. If there are substantial changes from the first run, it implies that this event and judgment is important to the future outcome of events.

There are different ways of calculating the cross-impact - see e.g. (Blanning \& Reinig, 1999; Han, 2001; Weimer-Jehle, 2005). Alarcon and Ashley derived a 7-point scale with index numbers from -3 to 3 . Considering the events in matrix form, the question becomes: "If column states were to occur how would this affect the probability of row states?" (Alarcon \& Ashley, 1998). The scale center, zero, represents no effect on row states when column states occur. The scale is mirrored around the center. The indexes $-3,-2$ and -1 represent a significant, moderate and slight decrease in the probability of the affected state, respectively, while +3 to +1 represent an increase in the probability in the same manner. Posterior probabilities are then calculated by analytical inferences and Monte Carlo simulations.

\section{Methodology}

The research is primarily quantitative, which entails developing a method to generate numerical measurements and analyzing and modelling the numerical data. Primary and secondary data sources were used during the work on this paper. The secondary data was in the form of academic research, reports by government agencies and other texts that were helpful in gaining insight into the topic and in creating a historical review and the underlying theories and methods that would guide the work. The primary data was gathered via two separate rounds of a questionnaire designed by the researcher. The participants formed a non-probability sample through purposive sampling, as experts on the matter at hand were sought. The former/earlier questionnaire was presented to experts as an internet survey with an introductory letter by email. The second round was presented only to respondents to the first round. Questions were omitted in the second round if wide consensus was expressed in their response to the first round, as will be further discussed in the next section.

\subsection{Research process}

One factor in conducting a successful Delphi study is the selection of participants (Gordon, 2009). For this study, the participants had to qualify as experts on matters related to developments in the Arctic Region. The original expert base is grounded/based on a purposive sample derived from a list of participants in the Arctic Center Conference 2013 (Grímsdóttir, 2014). Grímsdóttir (2014) conducted interviews with the experts to identify the parameters that could contribute to an abstraction of a decision model. Guðmundsson (2015) repeated the questionnaire with a larger sample of Arctic stakeholders by accumulating 236 e-mail addresses by internet search. The most critical parameters were identi- 
fied by the application of a Likert scale. Steinpórsdóttir (2017) applied the Delphi method on those eight (8) parameters which were critical for a cross-impact analysis. Members and heads of committees and institutes on matters relating to the Arctic region were sought, along with executives from the industry sector and politicians who have shown interest in developments in the Arctic. In total, 50 invitations to participate were sent out. The first round received 16 responses, including 1 partial response. The second round got even fewer responses - only 11, including 1 partial response. This was expected, as the more rounds are held, the more participants drop out (Gordon, 2009). However, the response rate was acceptable, as Iceland is a small country, so an abundance of experts is not to be expected.

Eight of the 28 impact factors were chosen for this study. These eight factors are all related to the Icelandic economy in the next 20 years and are as follows:

- Impact factor of oil and gas exploration

- Impact factor of tourism in the Arctic region

- Impact factor of cruise ships in the Arctic region

- Impact factor of fisheries in the Arctic region

- Impact factor of re-shifting of fish stocks in the Arctic region

- Impact factor of the need to monitor marine traffic (such as fishing vessels, ice breakers, cruise ships etc.)

- Impact factor of a transshipment port in Iceland

- Impact factor of cargo aircraft in the Arctic region

As seen from the list above, the impact factors do not represent single events, so a different approach to the cross-impact method was taken to evaluate their relationships. Rather than asking about occurrence, the respondents were asked to evaluate the impact one factor would have on the others.

The questions were in the following form (with question 1 as an example): How would oil and gas exploration in the Arctic region affect the impact of the following economic factors on the Icelandic economy in the near future (20 years)?

The other factors were listed below and the scale was from -3 to 3 with corresponding impacts as shown below:

-3 High negative impact

-2 Moderate negative impact

-1 Slight negative impact

0 No impact

+1 Slight positive impact

+2 Moderate positive impact

+3 High positive impact

Respondents also had an opportunity to give a reason for their estimate, and these were used along with survey data as feedback in round 2. The wording of questions was reviewed numerous times to ensure as far as possible that the wording was clear and that misunderstanding would be minimized.

Data from the first round of the survey had to be analyzed for delivering feedback in the second round of the survey. A box and whisker plot was constructed of judgment(s ?) on each interrelation between factors. A box and whisker plot shows the median of answers along with the interquartile range and the full range of answers. The interquartile range contains $25 \%$ of answers on each side of the median forming the "box". The "whisk- 
ers" are lines that show the full range of answers. Often the whiskers only represent a certain parameter around the interquartile range and outliers (data points that are outside of the range) are shown as single points. Since this research deals with expert judgment, the whiskers represent the range of answers given in the feedback. The respondents' sample is small, so one could argue that outliers should not be treated as mistakes or glitches, as is often the case in other applications. Along with the plots for each question, a summary of reasons given for different answers was also supplied. An example of the use of Box and Whisker plots may be found in (Petty et al, 2018).

\section{Results}

\subsection{Oil and gas exploration}

The first question was about how oil and gas exploration in the Arctic would impact the other factors with regard to the Icelandic economy over the next 20 years. The results of the first round can be seen in Figure 2. The answer median is shown in blue and the interquartile range as the box surrounding it. The whiskers, the lines outside the boxes, represent the full range of answers. The narrower the interquartile range, the smaller is the box in height, since this range covers $25 \%$ of answers above and below the median.

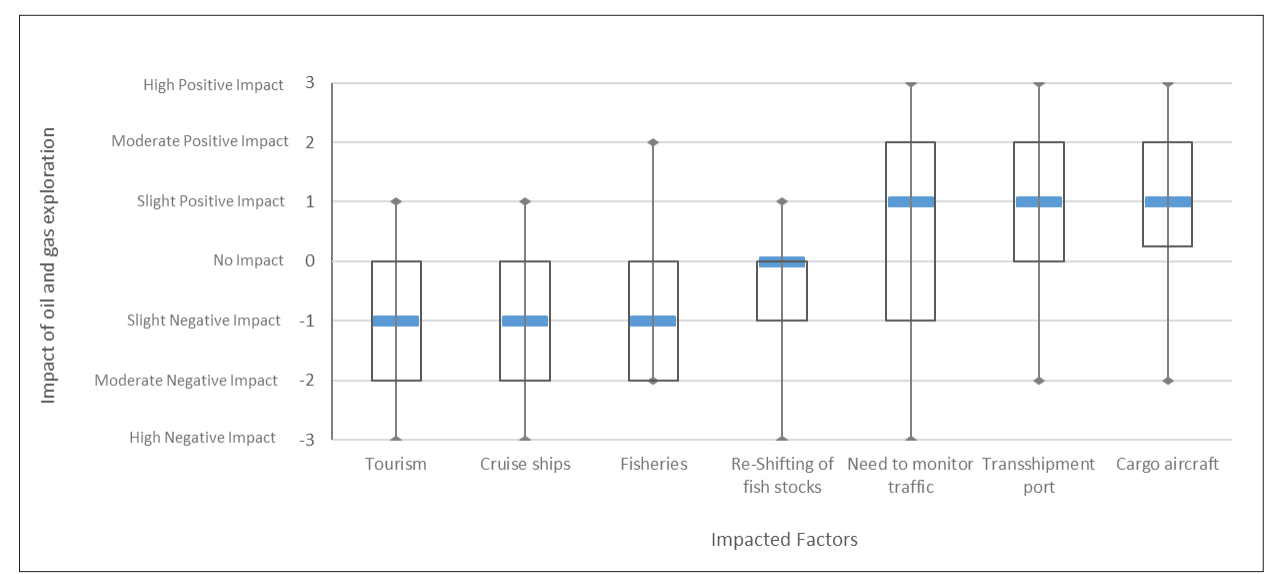

Figure 2. Impact of oil and gas exploration in the Arctic region - round 1

The range of judgments is quite extensive regarding impact on all other factors. The impact of oil on the need to monitor traffic spreads over the entire 7 point-scale of estimations, and the interquartile range stretches from slight negative impact to moderate positive impact. The impacts estimated in the second round can be seen in Figure 3.

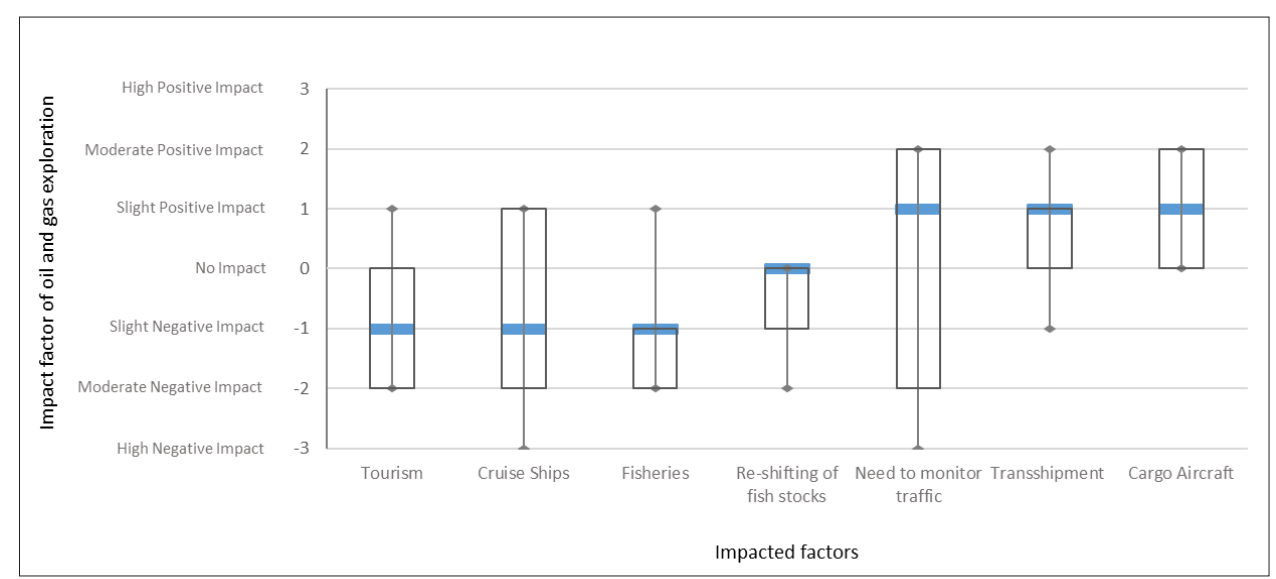

Figure 3. Impact of oil and gas exploration in the Arctic region - round 2 
Comments from the first round were fed back to participants in the second round, along with results from the first round, as shown in Figure 2. The median of answers did not change in the second round, but the breadth of responses reduced. The outcome of round 2 is seen in Figure 3.

In the second round, the distribution of answers was examined further and it revealed a split judgement on the impact of oil and gas exploration on cruise ships in the Arctic region, as seen in Figure 4. More experts predict it will have a negative impact on cruise ships but there is still a group that predicts a slight positive impact. Comparing this to answers from the first round, it is observed that participants have somewhat moved away from answering no impact and estimates have shifted from a moderate negative impact to a slight negative impact.

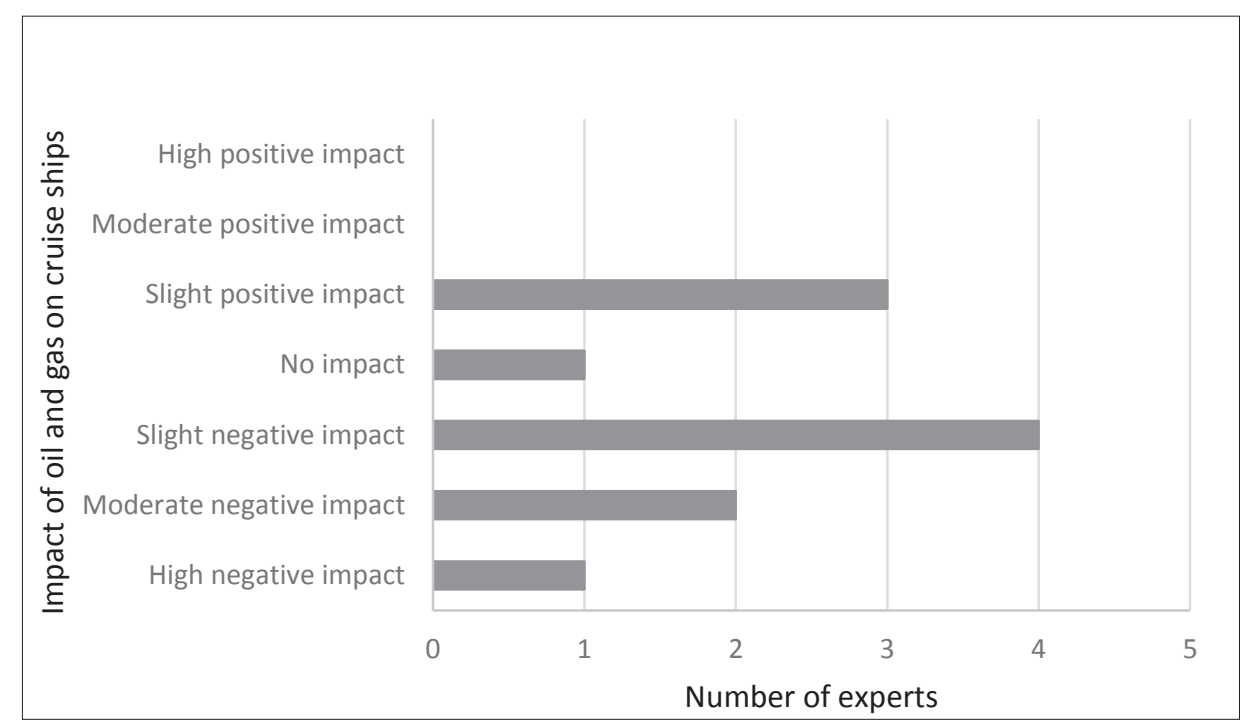

Figure 4. Distribution of answers on oil and gas impact on cruise ships

There is also a lack of consensus on the impact on the need to monitor marine traffic in the Arctic region. The majority believe it will have a slight or moderate positive impact. Those who believe it will have a negative impact say this will be moderate or high. Diversity among the answers is rather wide on this impact, as can be seen in Figure 5.

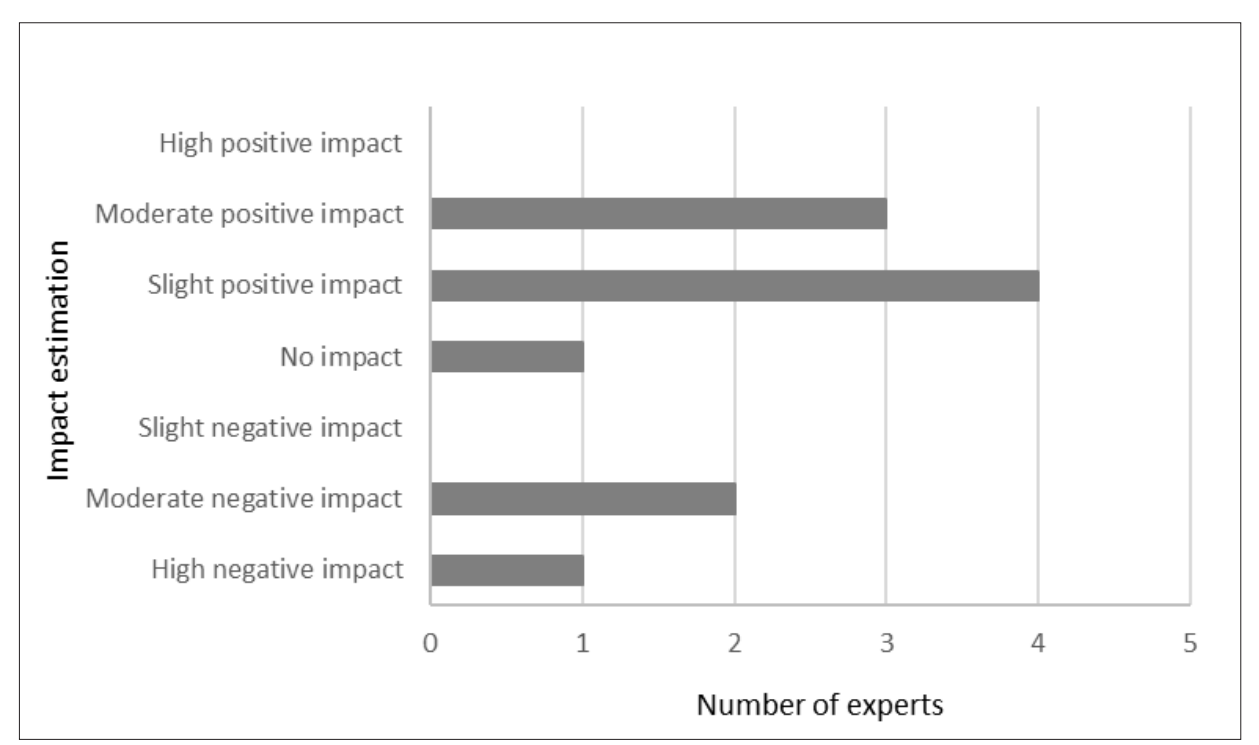

Figure 5. Distribution of answers regarding oil and gas impact on monitoring marine traffic 
Observe that in the rest of this section, only results from round 2 will be presented. All results can be retrieved from (Steinpórsdóttir, 2017).

\subsection{Tourism in the Arctic region}

The impact of tourism in the Arctic region on other factors, with regard to the Icelandic economy over the next 20 years was the subject of the second question. There was more consensus on the impact of tourism than on that of oil and gas in question 1. Participants were mostly in agreement about the impact of tourism on oil and gas exploration, fisheries and re-shifting of fish stocks. The majority of respondents, or $75 \%, 70 \%$ and $70 \%$ respectively, agreed that tourism would have no impact on these three factors. The estimation for other factors was more spread out. The impact on the need to monitor traffic has the widest interquartile range and stretches from no impact to moderate positive impact.

The impact of tourism on cruise ships ranged from moderate negative impact to high positive impact. However, most participants estimated the impact to be either slight or moderate positive. The cut off criteria allowed for only the impact of oil and gas exploration to be skipped in the second round of the questionnaire. Respondents gave reasons for their estimations in other categories, and since the Delphi method encourages exchange of opinion, these were kept through to the second round. The results of round 2 are displayed in Figure 6.

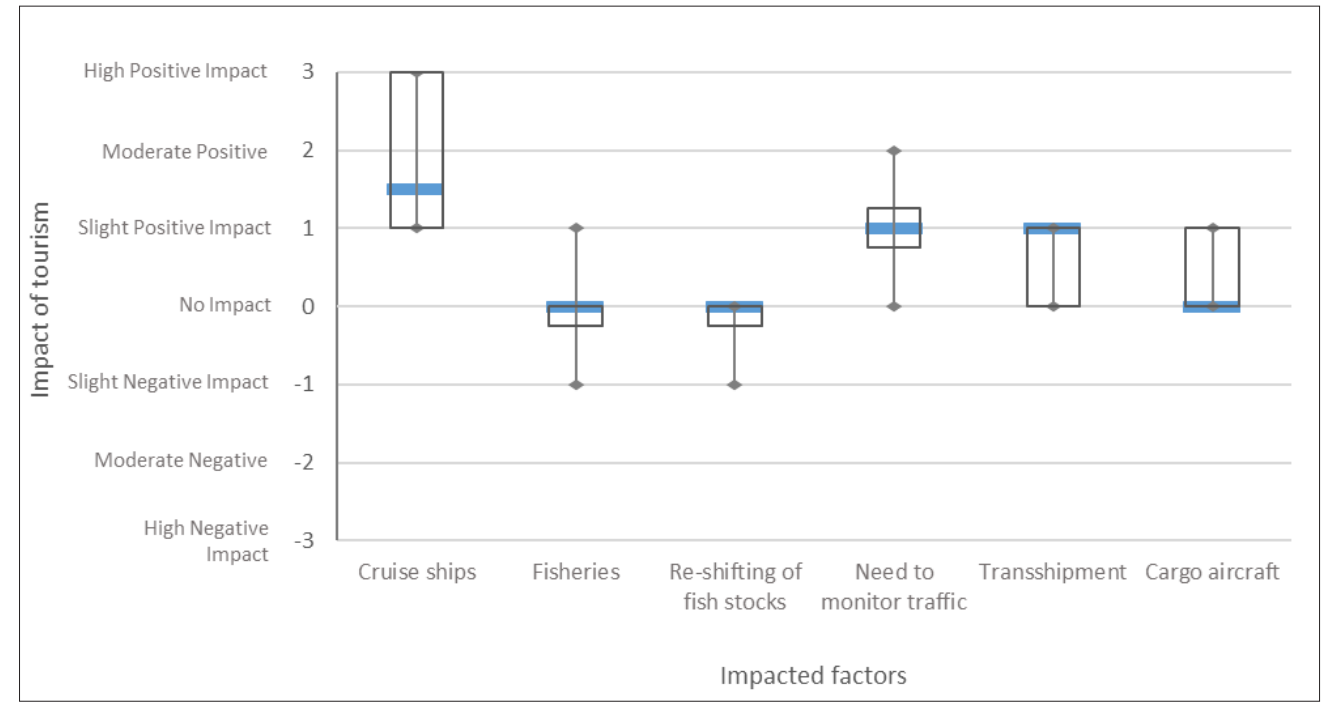

Figure 6. Impact of tourism in the Arctic region - round 2

The only impact that changed between rounds regarding the median value was the impact of tourism on a transshipment port in Iceland. The estimation went from no impact to slight positive impact. The range of answers decreased for most questions which were repeated, excluding the ones that already had a narrow answer range. The same can be said about the interquartile ranges. The impact of tourism on cruise ships is now between slight and moderate positive, with everyone agreeing it will be on the positive side. The average value is 1.8, however, so this impact is estimated as moderate positive impact for the cross-impact matrix.

\subsection{Cruise ships in the Arctic region}

Next, the impact of cruise ships in the Arctic region on other factors was estimated with regard to the Icelandic economy over the next 20 years. A high rate of consensus is reached regarding the impact of cruise ships on fisheries, re-shifting of fish stocks and cargo air- 
craft. This can be seen from the small/narrow interquartile range for each of these factors, and few or no estimations are outside of that range. The other impacted factors received a wider range of answers, with tourism and the need to monitor traffic being especially notable, since responses range from high positive impact to moderate negative impact. Estimation for these two impacts was requested again in the second round, as well as for oil and gas and transshipment. The outcome of the second round of replies is displayed in Figure 7.

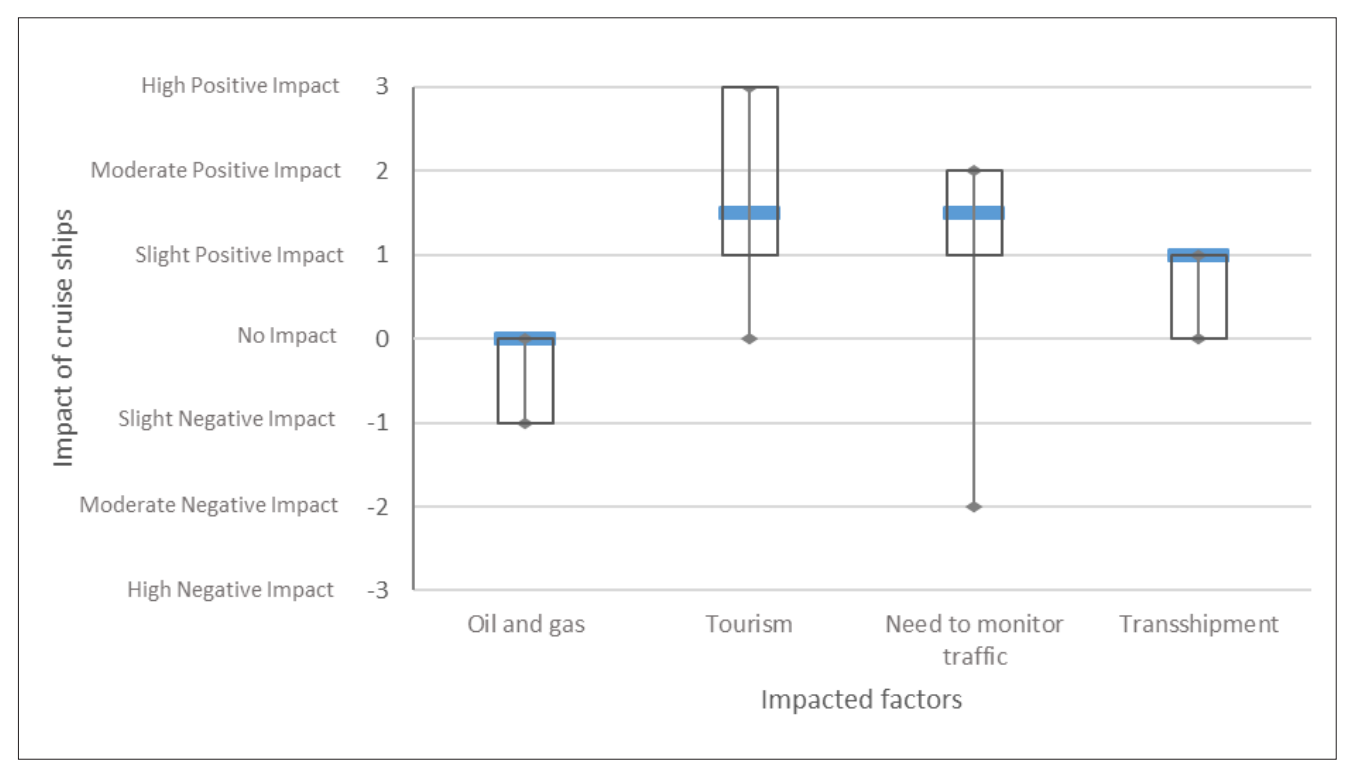

Figure 7. Impact of cruise ships in the Arctic region - round 2

The outcome of the second survey revealed a new value of median for 3 of the 4 impacts included in round 2, as seen in Figure 7. Estimates for the impact on tourism and the need to monitor marine traffic are still spread, although the interquartile range has decreased for monitoring of marine traffic. Due to fewer negative estimates of the impact of cruise ships on tourism in the Arctic, the interquartile range has moved upwards. The interquartile range for the impact on a transshipment port stays the same, however, consensus has moved towards a slight positive impact.

\subsection{Fisheries in the Arctic region}

Question 4 asked participants to estimate the impact of fisheries in the Arctic region on other factors, with regard to the Icelandic economy over the next 20 years. Consensus was reached on the impact of fisheries on tourism and cruise ships in the first round. The majority estimate was no impact, with $94 \%$ and $88 \%$ respectively. The majority estimate for the impact of fisheries on oil and gas was $56 \%$ at no impact. However, $44 \%$ voted for slight negative impact, and so participants were asked to consider the impact again. Other judgments got a wide range of estimates, so although the interquartile range was relatively small, participants were asked to re-evaluate, based on the outcome and reasons for estimates given as feedback. The outcome of round 2 is displayed in Figure 8. 


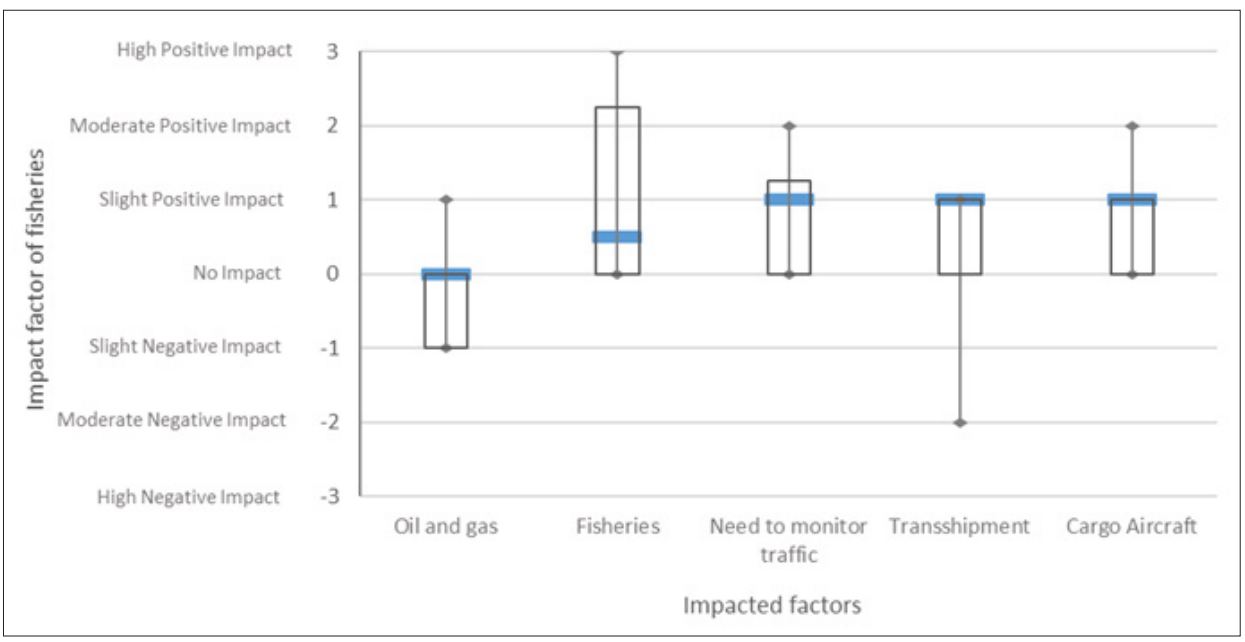

Figure 8. Impact of fisheries in the Arctic region - round 2

The median value for 3 of the 5 factors changed in the second round, as seen in Figure 4-10. Values moved slightly in the direction of positive impact and the range of answers decreased. Due to a researcher mistake in the survey, the impact of fisheries on re-shifting of fish stocks was not evaluated in the second round. Participants were instead asked to evaluate the impact of fisheries on fisheries. Some noticed, others did not, but the answers from the first round must be used as the result here.

\subsection{Re-shifting of fish stocks}

The outcome from the first survey on the impact of re-shifting of fish stocks on other factors with regard to the Icelandic economy over the next 20 years can be seen in Figure 9. The interquartile range for 4 out of 7 impacted factors only contains 1 estimate, that is no impact. This shows that a clear majority of respondents agreed regarding the impact on these factors.

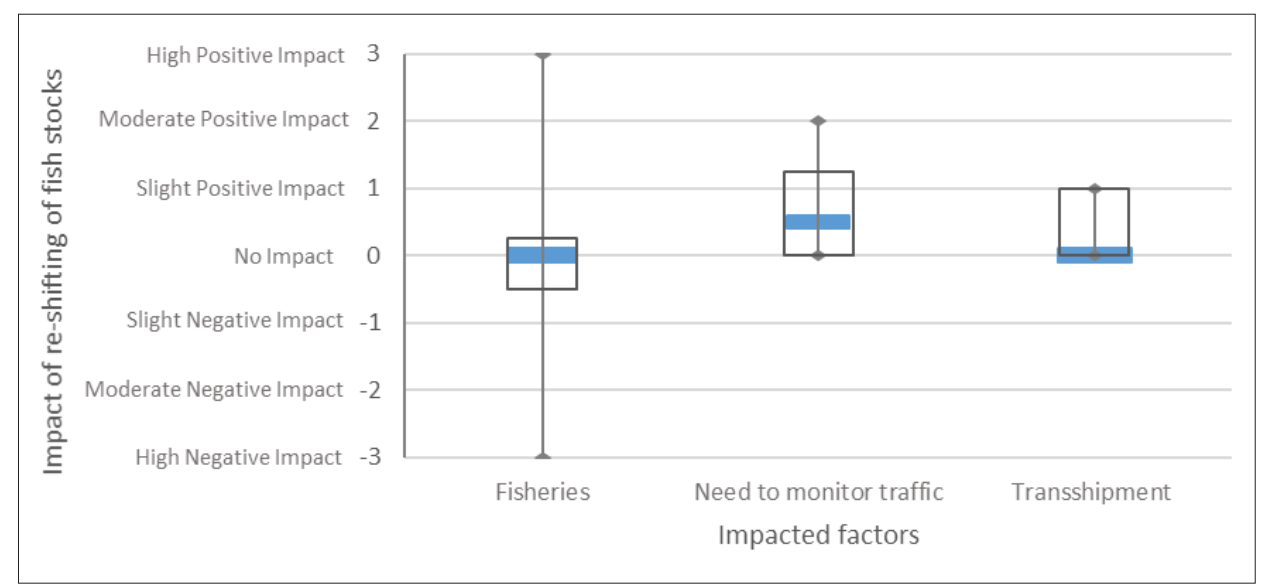

Figure 9. Impact of re-shifting fish stocks - round 2

The median value for each impact of re-shifting of fish stocks was concluded to be zero or no impact, except for the impact of re-shifting of fish stocks on the need to monitor marine traffic, where the impact is 0.5 , or between no impact and a slight positive impact. In this situation, it is helpful to look at the average value, which is 0.7 . This put the impact at slight positive rather than no impact. Again, the estimates for the impact of re-shifting of fish stocks on fisheries cover the range of the scale, but the interquartile range has decreased decidedly. 


\subsection{The need to monitor marine traffic}

Question 6 asked participants to estimate how the need to monitor marine traffic in the Arctic Region would affect other impact factors, regarding the Icelandic economy over the next 20 years. In line with the cut off criteria, participants were asked to reassess impacts for 4 of the 7 factors in the second round. Results can be seen in Figure 10.

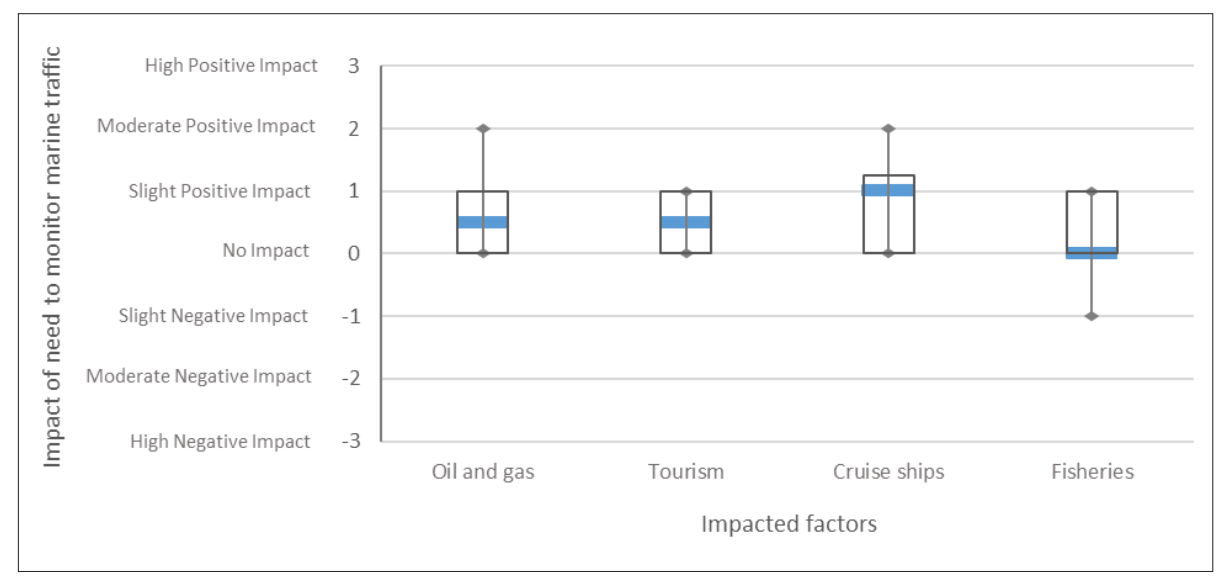

Figure 10. Impact of need to monitor traffic - round 2

As seen on the plots, participants moved towards greater consensus in the second round. The median values of impact on oil and gas and tourism have both moved to 0.5 . The average values are 0.6 and 0.5 respectively. Due to the average value, these impacts will be approximated as slight positive impacts in the cross-impact matrix presented later.

\subsection{Transshipment port in Iceland}

The impact of a transshipment port in Iceland on the other factors, with regard to the Icelandic economy over the next 20 years was the subject of question 7 . Judgments on the impact of a transshipment port in Iceland were quite diverse. The only consensus reached in the first round was the impact on re-shifting of fish stocks, and the conclusion was no impact. The other 6 impacted factors were included in round 2, and participants were asked to reassess their judgments. The outcome can be seen in Figure 11.

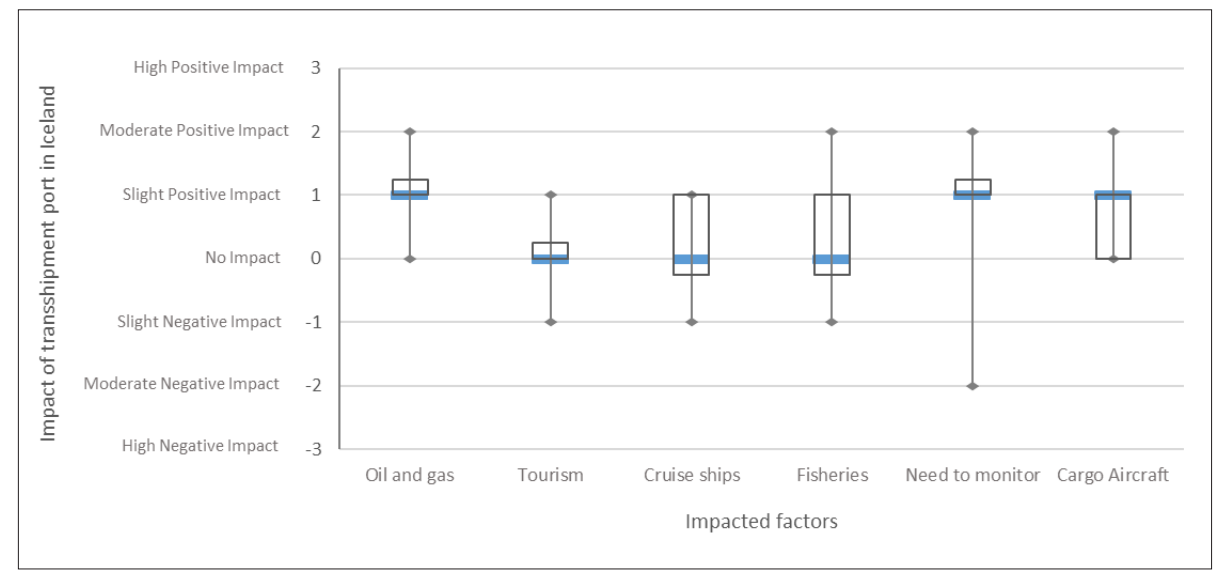

Figure 11. Impact of a transshipment port in Iceland - round 2

The median value for these impacts did not change between rounds, except for the impact on cargo aircraft, which moved from no impact to slight positive impact. However, judgments on the impact of a transshipment port in Iceland on fisheries and need to monitor marine traffic are still rather diverse. 


\subsection{Cargo aircraft in the Arctic region}

Lastly, participants were asked to estimate how cargo aircraft in the Arctic region would impact other factors with regard to the Icelandic economy over the next 20 years. The interquartile range for all impact judgments is reasonably small, suggesting some degree of consensus. However, criteria for consensus were not met, and participants were asked to consider their judgments again in round 2 . This was largely due to how evenly answers were distributed between the impacts estimated and the many comments given on reasons for judgments. These results can be seen in Figure 12.

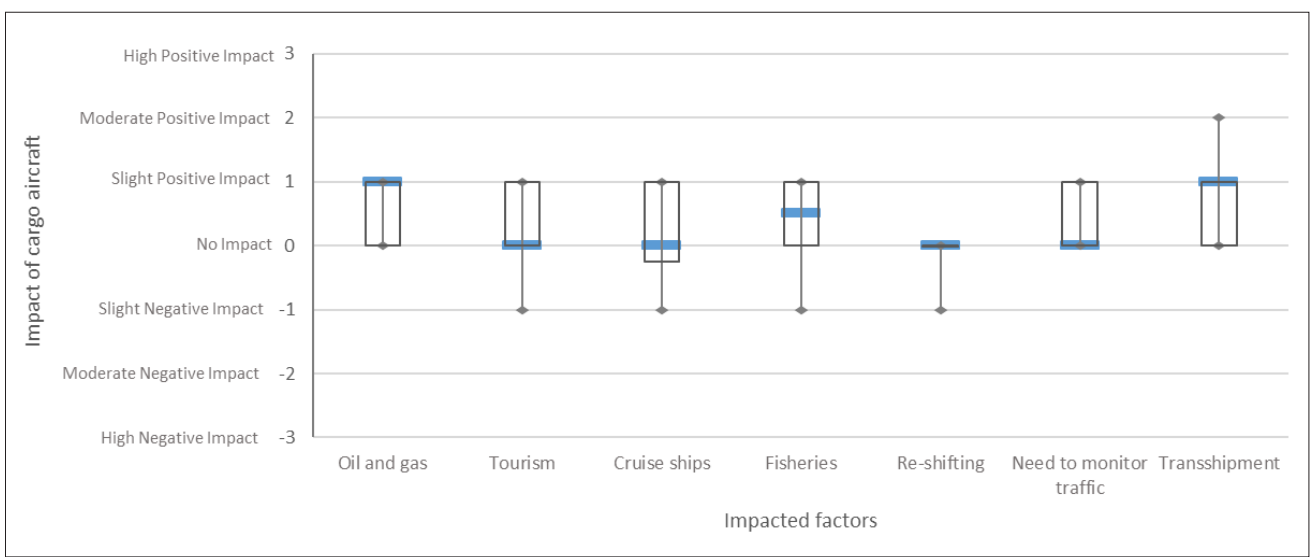

Figure 12. Impact of cargo aircraft in the Arctic region - round 2

The outcome of the second round satisfied the criteria for consensus. However, the median for impact rate did not change, apart from the impact of cargo aircraft on fisheries, which moved from a slightly positive impact to a position between no impact and slightly positive. The average for this impact is at 0.4 and therefore cargo aircraft are approximated as at no impact in the cross-impact matrix.

\subsection{Cross-impact matrix and interdependencies model}

The interdependencies of the impact parameters judged by the expert participants are represented in a cross-impact matrix and a model abstraction below. This is an attempt to gain an oversight of cross-impact relations between these factors.

The cross-impact matrix is displayed in Table 1 and the interdependencies model can be seen in Figure 13.

Table 1. Cross-impact matrix according to expert judgments

\begin{tabular}{|c|c|c|c|c|c|c|c|c|}
\hline $\begin{array}{l}\text { How will the row factors affect the } \\
\text { impact of column factors with } \\
\text { regards to the Icelandic economy in } \\
\text { the next } 20 \text { years? }\end{array}$ & \begin{tabular}{|c|} 
Oil and gas \\
exploration in the \\
Arctic region
\end{tabular} & $\begin{array}{l}\text { Tourism in the } \\
\text { Arctic region }\end{array}$ & $\begin{array}{l}\text { Cruise ships in } \\
\text { the Arctic region }\end{array}$ & $\begin{array}{l}\text { Fisheries in the } \\
\text { Arctic region }\end{array}$ & $\begin{array}{l}\text { Re-shifting of fish } \\
\text { stocks in the } \\
\text { Arctic region }\end{array}$ & $\begin{array}{l}\text { Need to monitor } \\
\text { marine traffic in } \\
\text { the Arctic }\end{array}$ & $\begin{array}{l}\text { Transshipment } \\
\text { port in Iceland }\end{array}$ & $\begin{array}{l}\text { Cargo aircraft in } \\
\text { the Arctic region }\end{array}$ \\
\hline $\begin{array}{c}\text { Oil and gas exploration in the } \\
\text { Arctic region }\end{array}$ & & SLI- & SLI- & SLI- & No Impact & SLI+ & SLI+ & SLI+ \\
\hline Tourism in the Arctic region & No Impact & & MOD+ & No Impact & No Impact & SLI+ & SLI+ & No Impact \\
\hline $\begin{array}{l}\text { Cruise ships in the Arctic } \\
\text { region }\end{array}$ & No Impact & MOD+ & & No Impact & No Impact & SLI+ & SLI+ & No Impact \\
\hline Fisheries in the Arctic region & No Impact & No Impact & No Impact & & No Impact & SLI+ & SLI+ & SLI+ \\
\hline $\begin{array}{l}\text { Re-shifting of fish stocks in } \\
\text { the Arctic region }\end{array}$ & No Impact & No Impact & No Impact & No Impact & & SLI+ & No Impact & No Impact \\
\hline $\begin{array}{l}\text { Need to monitor marine } \\
\text { traffic in the Arctic }\end{array}$ & $\mathrm{SLI}+$ & $\mathrm{SLI}+$ & SLI+ & No Impact & No Impact & & $\mathrm{SLI}+$ & No Impact \\
\hline $\begin{array}{l}\text { Transshipment port in } \\
\text { Iceland }\end{array}$ & SLI+ & No Impact & No Impact & No Impact & No Impact & SLI+ & & SLI+ \\
\hline $\begin{array}{c}\text { Cargo aircraft in the Arctic } \\
\text { region }\end{array}$ & SLI+ & No Impact & No Impact & No Impact & No Impact & No Impact & SLI+ & \\
\hline
\end{tabular}


The cross-impact matrix provides a better overview of the parameters studied. According to the expert judgments, none of the parameters impact re-shifting of fish stocks, and only one parameter, oil and gas exploration, impacts fisheries in the Arctic Region. Oil and gas exploration in the Arctic is also the only parameter concluded to have a negative impact on other parameters. Tourism in the Arctic Region and cruise ships in the Arctic Region have a moderate positive impact on one another. Moderate positive impact is the highest impact observed in the study, and no impact between parameters is the most frequent judgment.

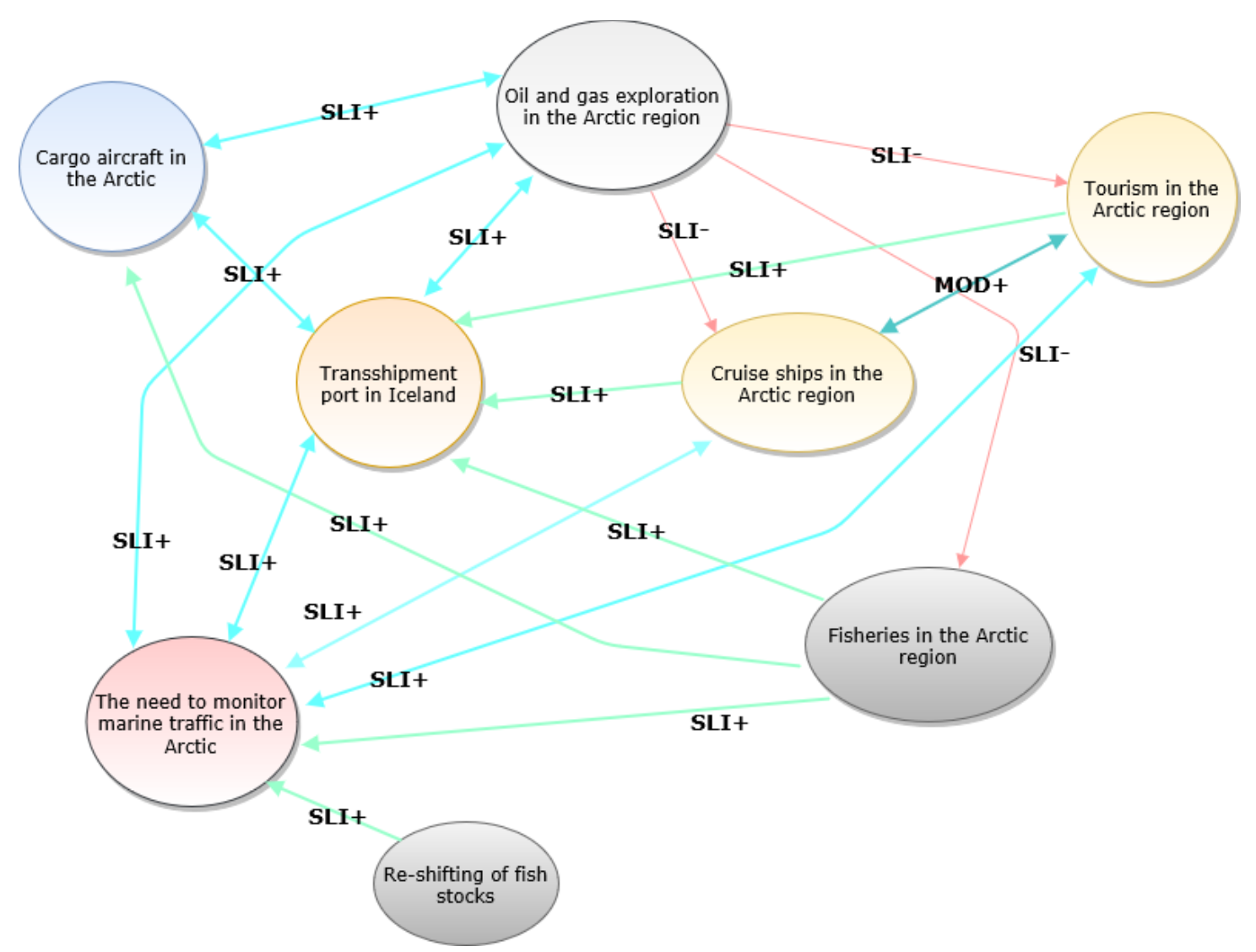

Figure 13. Cross-impacts of factors inherent in this study

Figure 13 displays the same information as the cross-impact matrix in Table 1 . The light green arrows represent a slight positive impact from one parameter to the other, but the light blue arrows represent a slight positive impact both ways between parameters. The red arrows represent a slight negative impact of one parameter on the other. The only arrow in turquoise shows a reinforcing moderate positive impact between tourism and cruise ships in the Arctic. The parameter of re-shifting of fish stocks was close to not being part of the system, but was concluded to have a slight positive impact on the need to monitor marine traffic in round 2 of the survey.

\subsection{Discussion}

The results from the Delphi method showed that in many cases it does induce a larger degree of consensus, but if strong opinions are held, people are less likely to divert from them. The feedback given from the first round clearly influenced the results of the second rounds. However, it is difficult to say whether people considered their evaluation again carefully, or were simply swayed by the comments given and the results from the first round. Of course, one must trust that participants answered to the best of their knowledge 
in both rounds. The respondent rate was 16 out of 50 or 32\% in the first round and 11 out of 50 or $22 \%$ in the second round, which is in line with what is to be expected in Delphi studies. The respondent rate could possibly have been improved by taking the time to recruit experts in a more personal manner, via a phone call, for instance, or by offering a reward for participation. However, the former could be extremely time consuming and the second dependent on the resources of the researcher. As is often the case in surveys, participants are cautious in their judgments and shy away from extreme values, unless they hold strong opinions on certain issues. This study was probably no different, as the impact values ranged between slight negative impact and moderate positive impact. The median impact values must not be taken as absolute, as the interquartile ranges must also be considered, as well as the extreme opinions, since these are expert judgments, but not repeated processes in controlled settings. Consensus on estimation should indicate less uncertainty. However, in some cases it can be a sign of experts compromising instead of arguing to support their opinion. The wording of questions is also crucial to minimizing misunderstanding. In complex cases, such as the Arctic, where definition of parameters is somewhat conceptual, the possibility of experts from different disciplines having conflicting points of view in understanding questions is greater. Delphi does, however, resist this by having participants explain their views on the subject. The impact factor of re-shifting of fish stocks had a median of no impact on other factors, except (I think) for the need for monitoring marine traffic, where the impact was slight positive. Other parameters were considered to have no impact on the re-shifting of fish stocks.

When looking at the range of answers and the comments given as reasons for judgments it is obvious that the reason is not that it (not sure what "it" is - not clear ) is not relevant. Many participants were confused by the wording, although it was similar to the wording of earlier research by Grímsdóttir (2014) and Guðmundsson (2015). In further research, this factor should rather be named 're-shifting of fish stocks further towards the Arctic ', since this wording implies that it would stay within areas in which Iceland could gain quota rights. Possibly, it should even be defined in more detail with help from experts via interviews, since comments were made that it would matter which species of fish were moving. The main limitation to this research is the number of parameters it explores.

As the cross-impact method is time demanding on participants, it was concluded that estimating cross-impacts of eight parameters would be applicable. The selection of parameters is a difficult task, since parameters excluded might be of great importance to the system, and parameters included could be of little value for the research.

This research did not focus on heuristic calculations of the cross-impact matrix. The cross-impact matrix is constructed from the expert opinions, and further mathematical inferences are left to other researchers. The reason for this is that the focus was rather on constructing the questions and gaining an overview of the parameters. If there is interest in the cross-impact matrix, it can (I think) be calibrated by using methods from Alarcon and Ashley (1998), for example. Initial probabilities and odds could be approximated from former research and the impact values from this research used to calculate new odds. Scenarios could be derived and parameters manipulated. However, it is debatable how much these calculations would achieve, since only 8 out of 28 impact factors and their cross-impacts have been estimated. Heuristic and inference methods have also been criticized, since the output ultimately depends on the input, and often the most intricate part of the analysis is figuring out which set of events to include and exclude, and how to ask the right questions.

The significance of the small sample must also be underlined, as only 11 people participated in the second round of the Delphi survey. All participants were Icelandic, and throughout the research period, spanning three years, it became apparent that even though the sample was carefully designed to include opinions from government, academia and industry, experts from these sectors are not equally willing to reserve time to participate in 
the surveys. The risk of an opinion bias can therefore not be ruled out, and further testing of the viability of the parameters and the cross-impact strength is needed.

The results comply to a fair degree with other discussions on the impact on economic activities in the Arctic, see, e.g. (Eskeland \& Flottorp, 2006). However, it must be stressed that the majority of accessible studies on the impact of the prevailing climate changes focus on the ecosystem and mitigation strategies to preserve and/or to adapt (EEAS, 2017). A stochastic decision model where probabilistic (what if) parameters are connected can therefore contribute to comprehending the different outcomes based on different scenarios. The future of the Arctic is uncertain, and contradictory debates are frequent. Uncertainty regarding the future of the Arctic calls for a scenario-based planning approach. In spite of the model abstraction being based on Icelandic opinions, the model can be scaled to include other parts of the Arctic if the statistics are available.

\section{Conclusion}

The aim of this project was to explore formerly defined economic parameters to aid in the construction of an open access decision model for strategic planning in the Arctic region. The Delphi and cross-impact methods were chosen, since other data on influences in the Arctic region is not available, and research must rely on expert opinions. As always, where predictions of the future are concerned, the uncertainty level is high, and expert judgments should not be interpreted as facts, but as nothing more or less than a synthesis of opinions.

The most important outcome of this research is the identification of eight significant impact factors and their alleged relationsship. Each of the parameters chosen for this research should be considered in further work on the development of a decision model, since all of them carry a level of uncertainty and impact some of the other parameters. Still to be discovered are the impacts between these eight and the other twenty parameters not included in this research. Further work is therefore needed to formulate the mathematical relationship between the parameters, in order to build a platform for stochastic simulations.

The final words to sum up the conclusion of this research are from Ronald A. Howard (1980): "The overall aim of decision analysis is insight, not numbers".

\section{References}

ACIA. (2004). Impacts of a Warming Arctic: Arctic Climate Impact Assessment. Retrieved from http://www. amap.no/documents/doc/impacts-of-a-warming-arctic-2004/786

Alarcón, L. F., \& Ashley, D. B. (1998). Project management decision making using cross-impact analysis. International Journal of Project Management, 16(3), 145-152. doi:10.1016/S0263-7863(97)00045-8

AMAP, Arctic Monitoring and Assessment Programme. (1998). AMAP Assessment Report: Arctic Pollution Issues. Retrieved from http://www.amap.no/documents/doc/amap-assessment-report-arctic-pollution-issues/68

Arctic Council. (2016). The Arctic Council: A backgrounder. Retrieved May 8, 2016 from http://www.arctic-council.org/index.php/en/about-us

Bañuls, V. A., \& Turoff, M. (2011). Scenario construction via Delphi and cross-impact analysis. Technological Forecasting and Social Change, 78(9), 1579-1602. Retrieved from http://www.sciencedirect.com/science/article/pii/S0040162511000667

Blanning, R. W., \& Reinig, B. A. (1999). Cross-impact analysis using group decision support systems: an application to the future of Hong Kong. Futures, 31(1), 39-56. doi:10.1016/S0016-3287(98)00109-8

Comiso, J. C. (2012). Large Decadal Decline of the Arctic Multiyear Ice Cover. Journal of Climate, 25, 1176-1193. doi: 10.1175/JCLI-D-11-00113.1.

Cuhls, K. (2005). The Delphi Method. In Cuhls, K. (ed.), Delphi Surveys. Teaching material for UNIDO foresight seminars (pp. 93-112). Retrieved from http://www.unido.org/fileadmin/import/16959_DelphiMethod.pdf

Dallmann, W. K. (n.d.). Arctic administrative areas. Retrieved from http://www.arctic-council.org/index.php/ en/learn-more/maps

Daston, L. (1988). Classical Probability in the Enlightenment. Princeton: Princeton University Press.

Ding, Q., Schweiger, A., L'Heureux, M., Battisti, D. S., Po-Chedley, S., Johnson, N. C., Blanchard-Wriggles- 
worth, E., Harnor, K., Zhang, Q, Eastman, R., \& Steig, E. J. (2017). Influence of high-latitude atmospheric circulation changes on summertime Arctic sea ice. Nature Climate Change, 7, 289-295. Retrieved from https://www.nature.com/articles/nclimate3241

Edwards, W. (1954). The theory of decision making. Psychological Bulletin, 51(4), 380-417. doi:10.1037/h0053870

Ellis, B., \& Brigham, L. (2009). Arctic marine shipping assessment 2009 report. Retrieved from http://www. pame.is/images/03_Projects/AMSA/AMSA_2009_report/AMSA_2009_Report_2nd_print.pdf

EEAS. (2017). European External Action Service, Climate Change and the Arctic Environment. Retrieved from https://eeas.europa.eu/arctic-policy/eu-arctic-policy/20955/climate-change-and-arctic-environment_en.

Eskeland, G. S., \& Flottorp, L. S. (2006). Climate change in the Arctic: A discussion of the impact on economic activity. In S. Glomsrød and I. Aslaksen (eds.), The Economy of the North (p. 86). Oslo: Statistics Norway.

French, S. (1995). Uncertainty and Imprecision: Modelling and Analysis. The Journal of the Operational Research Society, 46(1), 70-79. doi:10.2307/2583837

Goodwin, P., \& Wright, G. (2004). Decision Analysis for Management Judgment (3rd ed.). West Sussex, England: John Wiley \& Sons Ltd.

Gordon, T. J. (1994). Cross-Impact Method. In Jerome C. Glenn and Theodore J. Gordon (eds.), Futures research methodology. Retrieved from http://citeseerx.ist.psu.edu/viewdoc/download?doi=10.1.1.202.7337\&rep $=$ rep $1 \&$ type $=$ pdf

Gordon, T. J. (1994). The Delphi method. In J. C. Glenn and T. J. Gordon (eds.), Futures research methodology. Retrieved from http://www.gerenciamento.ufba.br/downloads/delphi_method.pdf

Gordon, T. J. (2009). The Delphi method. In J. C. Glenn and T. J. Gordon (eds.), Futures research methodology, Version 3. Retrieved from http://millennium-project.org/FRMv3_0/04-Delphi.pdf

Grímsdóttir, H. (2014). Requirement Analysis of an open access decision model for the Arctic Region (Master's thesis). Reykjavík University, School of Science and Engineering. Retrieved from http://hdl.handle.net/1946/17340

Guðmundsson, S. V. (2015). Decision Model for the Arctic - Cross Impact Analysis (Master's thesis). Reykjavík University, School of Science and Engineering. Retrieved from http://hdl.handle.net/1946/20513

Han, S. H. (2001). A risk-based entry decision model for international projects. KSCE Journal of Civil Engineering, 5(1), 87-96. doi:10.1007/BF02830730

Hansson, S. O. (1994). Decision Theory: A Brief Introduction. Stockholm: KTH Royal Institute of Technology. Retrieved from http://people.kth.se/ soh/decisiontheory.pdf

Holthus, P., Clarkin, C., \& Lorentzen, J. (2013). Emerging Arctic Opportunities: Dramatic increases expected in Arctic shipping, oil and gas exploration,fisheries, and tourism. Proceedings of the Marine Safety and Security Council, 70(2), 10-13

Howard, R. A. (1980). An Assessment of Decision Analysis. Operations Research, 28(1), 4-27. Retrieved from http://www.jstor.org/stable/172135

Howard, R. A. (1966). Decision analysis: Applied decision theory. In D. B. Hertz and J. Melese (eds.), The Proceedings of the Fourth International Conference on Operational Research (pp. 97-113). New York: John Wiley \& Sons, Inc. Retrieved from https://www.sdg.com/wp-content/uploads/2015/06/Decision-Analysis-Applied-Decision-Theory.pdf

Howard, R. A. (1988). Decision Analysis: Practice and Promise. Management Science, 34(6), 679-695. Retrieved from http://www.jstor.org/stable/2632123

Hsu, C., \& Sandford, B. A. (2007). The Delphi Technique: Making Sense of Consensus. Practical Assessment Research \& Evaluation, 12(10). Retrieved from http://pareonline.net/getvn.asp?v=12\&n=10

Jóhannesdóttir, L., \& Cook, D. (2015). An insurance perspective on Arctic opportunities and risks: hydrocarbon exploration and shipping. Iceland: Institute of International Affairs, The Centre for Arctic Policy Studies, University of Iceland. Retrieved from http://ams.hi.is/wp-content/uploads/2015/04/An_Insurance_Perspective_PDF.pdf

Keeney, R. L. (1982) Decision Analysis: An Overview. Operations Research, 30(5), 803-838. doi:10.1287/ opre.30.5.803

Lajeunesse, A. (2012). A New Mediterranean? Arctic Shipping Prospects for the 21st Century. Journal of Maritime Law and Commerce, 43(4), 521-537.

Laulajainen, R. (2009). The Arctic Sea Route. Int. J. Shipping and Transport Logistics, 1(1), 55-73. doi:10.1504/ IJSTL.2009.021976

Lloyd's. (2011). Arctic Opening: Opportunity and Risk in the High North. Lloyd's One Lime Street London EC3M 7HA.

NSIDC, National Snow and Ice Data Center. (2016). SOTC: Sea Ice. Retrieved May 8, 2016 from http://nsidc. org/cryosphere/sotc/sea_ice.html

NSIDS, National Snow and Ice Data Center. (2017). Arctic Sea Ice Extent (Area of Ocean with at least 15\% sea ice). Retrieved April 28, 2017, from http://nsidc.org/arcticseaicenews/charctic-interactive-sea-ice-graph/

Ore, O. (1960). Pascal and the Invention of Probability Theory. The American Mathematical Monthly, 67(5), 409419. doi:10.2307/2309286

Petty, A. A., Stroeve, J. C., Holland, P. R., Boisvert, L. N, Bliss, A. C., Kimura, N., \& Meier, N. M. (2018). The Arctic sea ice cover of 2016: a year of record-low highs and higher-than-expected lows. The Cryosphere, 12, 433-452. 
Robson, C. (2011). Real World Research: A Resource for Users of Social Research Methods in Applied Settings (3rd ed.). West Sussex, England: John Wiley \& Sons Ltd.

Schoemaker, P. J. H. (1982). The Expected Utility Model: Its Variants, Purposes, Evidence and Limitations. Journal of Economic Literature, 20(2), 529-563. Retrieved from http://www.jstor.org/stable/2724488

Shortall, R., Davidsdottir, B., \& Axelsson, G. (2015). A sustainability assessment framework for geothermal energy projects: Development in Iceland, New Zealand and Kenya. Renewable and Sustainable Energy Reviews, 50, 372-407

Steinpórsdóttir, F. D. (2017). Economic Impact Factors Regarding the Arctic Region Cross-Impact Study via the Delphi Method (Master thesis). Reykjavík University, School of Science and Engineering. Retrieved from http:// hdl.handle.net/1946/28774

Turoff, M. (1972). An Alternative Approach to Cross-Impact Analysis. Technological Forecasting and Social Change, 3(3), 309-339.

Weimer-Jehle, W. (2006). Cross-Impact Balances: A System-Theoretical Approach to Cross-Impact Analysis. Technological Forecasting and Social Change, 73(4), 334-361. doi:10.1016/j.techfore.2005.06.005

Yousuf, M. I. (2007). Using Experts' Opinions through Delphi Technique. Practical Assessment Research E Evaluation, 12(4). Retrieved from http://pareonline.net/getvn.asp?v=12\&n=4 
